\title{
Letramento cientifico e simplificação textual: - papel do tradutor no acesso ao conhecimento cientifico
}

Scientific literacy and textual simplification: the role of the translator in the access to scientific knowledge

Maria José Bocorny Finatto

Universidade Federal do Rio Grande do Sul

Aline Evers

Universidade Federal do Rio Grande do Sul

Monica Stefani

Universidade Federal do Rio Grande do Sul

Resumo: A partir de um exercício de aula que envolveu simplificar um texto científico em português sobre a Doença de Parkinson (DP) para compreensão por leitores brasileiros leigos de baixa escolaridade, realizado com acadêmicos de tradução, em meio às suas atividades de Educação a Distância (EAD), estabelecemos uma relação entre os conceitos de tradução intralinguística, letramento científico e simplificação textual. Para tanto, destacamos as diferenças encontradas na simplificação textual feita de dois modos, com e sem suporte de ferramentas digitais, e refletimos sobre o envolvimento desses alunos nas tarefas e sobre a formação de tradutores como mediadores/intermediários do conhecimento.

Palavras-chave: Acessibilidade à informação. Letramento científico. Simplificação textual. Tradução intralinguística.

Abstract: From the task given to students of the translation course of simplifying a scientific text on Parkinson's disease written in Brazilian Portuguese to be understood by lay Brazilian readers with low levels of education, we seek to interrelate the concepts of intralinguistic translation, scientific literacy and textual simplification. We highlight the differences found in the textual simplification performed in two ways, with and without digital tools, and think about the student's engagement in those tasks as well as the training of translators as knowledge mediators/intermediaries.

Keywords: Textual simplification. Scientific Literacy. Information Accessibility. Intralinguistic Translation. 


\section{Introdução}

Este artigo traz o relato de um experimento pontual com a leitura e a simplificação, por um grupo de estudantes de Letras/Tradução, de Maria José um texto científico em português sobre a Doença de Parkinson (DP). A Bocorny proposta da simplificação do texto foi torná-lo acessível para leitores Finatto brasileiros adultos de baixa escolaridade e pouco hábito de leitura. 0 Aline Evers Educação a Distância (EAD) na qual buscamos a promoção da leitura em ambientes digitais, propondo e verificando estratégias para um maior Monica envolvimento de estudantes de Tradução/Letras em tarefas on-line. AsStefani sim, tratamos também de letramento digital e letramento científico. Para a pesquisa, realizada ao longo de 12 meses, utilizamos textos cien136 tíficos e de divulgação para leigos, sobre o tema da DP, tendo contado com o apoio da Secretaria de Educação a Distância (SEAD) da UFRGS, no âmbito do Edital 21/2015, no projeto intitulado Leitura e compreensão de tarefas em ambientes de ensino on-line: desafios para a adesão do aluno. Como o experimento pontual envolveu a tarefa de simplificar um texto científico, previamente lido e terminologicamente estudado em meio às atividades da disciplina obrigatória Terminologia Aplicada, tendo-se em mente um leitor de baixa escolaridade, dinamizou-se uma série de questões em meio à tarefa colocada. Trataremos dessas questões a seguir.

Com esses estudantes de Tradução, tentamos, por um lado, discutir sobre a importância de se oferecer informação textual escrita sobre temas de Saúde Pública em formatos especiais, mais facilitados, para públicos de menor escolaridade. Esse processo pode representar uma oportunidade de trabalho para um profissional de Letras que atue como terminólogo e/ou redator técnico. Do mesmo modo, buscamos mostrar as críticas a respeito dessa necessidade de "simplificar as mensagens", prática que alguns entendem popularmente como "vulgarizar" ou "nivelar por baixo". Por outro lado, ao implementar o exercício com esses estudantes, quisemos verificar as melhores alternativas para conquistar sua adesão à tarefa, observar em que medida exibiriam letramento científico, como também verificar como desempenhariam a leitura e a reescrita propostas com e sem acesso a recursos da internet.

No que segue, a estrutura deste artigo é a seguinte: a) apresentamos um quadro das noções teóricas envolvidas, como a problemática da vulgarização ou popularização científica e a compreensão de leitura, tradução intralingual e um quadro geral do desenho do nosso experi- 
mento; b) apresentamos trabalhos sobre letramento científico, sobre simplificação e leitura tradutória que foram referências em estudo prévio com os estudantes envolvidos no experimento; c) relatamos o experimento passo a passo e discutimos seus resultados; e, por fim, em d) sintetizamos o todo da pesquisa realizada, apontando suas conclusões e contribuições para o âmbito dos estudos sobre Leitura e para as pesquisa em EAD.

\section{Acessibilidade à informação científica, simplificação e acesso à internet}

Embora seja um tema de extrema relevância, a promoção da acessibilidade à informação, especialmente a informação sobre temas científicos, através da simplificação da linguagem e dos textos escritos, ainda

Letramento cientifico e simplificação textual é um tópico tratado com muitas restrições e cercado de polêmicas que não são nada recentes. Isso porque se envolve aqui um tema como a vulgarização científica, algo que, vinculado a um valor pejorativo, mobiliza os brasileiros desde longa data, conforme vemos no trabalho de De Rezende Vergara (2008). Nesse trabalho, vemos que há historicamente uma aproximação de sentido entre vulgarizar e reduzir, chegando-se até a noção de prostituir-se. Hoje não faltam pessoas que considerem que popularizar assuntos científicos seria o mesmo que caricaturizá-los, perdendo-se, assim, os conhecimentos mais "sérios".

A despeito da polêmica histórica e da dicotomia entre divulgação científica e vulgarização científica, no âmbito dos Estudos da Linguagem e também em outras áreas de conhecimento, como o Processamento da Linguagem Natural, em Ciência da Computação, para alcançar a acessibilidade de informação textual escrita, existem propostas que vão desde a simplificação do texto, com trocas de estruturas linguísticas e de vocabulário, até a apresentação das informações em diferentes formatos - como a inclusão de imagens e outros recursos audiovisuais, como os infográficos.

Independentemente dessas polêmicas, cada vez mais o cidadão brasileiro tem acesso à informação textual escrita, em especial graças à popularização da internet. Apesar disso, uma pesquisa recente da FECOMÉRCIO ${ }^{1}$ sinaliza-nos que $70 \%$ dos brasileiros não chegaram a ler um livro completo em um ano. Isso pode demonstrar que

1 Pesquisa realizada em 2007 pela Fecomércio do Rio de Janeiro. 
Maria José

Bocorny

Finatto

Aline Evers

Monica

Stefani

138

esse acesso à informação não significaria, necessariamente, acesso ao conhecimento, pelo menos no que diz respeito ao conhecimento divulgado em formato de livro. Noutra direção, uma pesquisa de 2010 do Ministério da Ciência e Tecnologia ${ }^{2}$ contabilizava um aumento de $41 \%$ para $65 \%$ no interesse dos brasileiros por ciência. No entanto, a maioria dos entrevistados não sabia citar nenhuma instituição científica ou mesmo o nome de algum(a) cientista importante. Além disso, uma pesquisa muito mais recente, noticiada em março de 2016, nos dá conta de que, infelizmente,

apenas $8 \%$ das pessoas em idade de trabalhar são consideradas plenamente capazes de entender e se expressar por meio de letras e números. Ou seja, oito a cada grupo de cem indivíduos da população. Eles estão no nível "proficiente”, o mais avançado de alfabetismo funcional em um índice chamado Inaf (Indicador de Alfabetismo Funcional) ${ }^{3}$.

Esses dados sugerem que o acesso ao conhecimento por meio da leitura fica ainda restrito a uma pequena parcela da população brasileira. Essa, além de ter acesso à internet, teria acesso a uma educação diferenciada e teria passado por uma formação leitora considerada privilegiada. Ao que parece, mesmo exposta a textos, a livros, seja na internet ou em suporte físico, apenas uma pequena parcela dos brasileiros consegue interagir qualificadamente com a informação que recebe. Poucos entendem o que leem, por vários motivos.

Essa assimetria entre um acesso massificado à internet versus o acesso restrito ao conhecimento cria uma demanda de trabalho intensa de educadores. Há um desafio de mitigar as desigualdades e promover ações que permitam que o acesso livre às informações também signifique acesso livre ao conhecimento. Qualificar a educação do cidadão brasileiro, especialmente nos anos da Educação Básica, parece ser a grande lacuna a preencher para se promover um acesso verdadeiro ao conhecimento, do qual as pessoas se apossem e sobre o qual construam novas experiências.

2 Dados disponíveis em http://www.mct.gov.br/upd_blob/0214/214770.pdf. Acesso em 6 mar. 2016. 3 Disponível em: http://download.uol.com.br/educacao/2016_INAF_\%20Mundo_do_Trabalho.pdf. Acesso em 6 mar. 2016. Pesquisa realizada em 2015 com 2 mil pessoas pelo Instituto Paulo Montenegro (IPM) e pela ONG Ação Educativa. 
Nesse estado de realidade, inserem-se a nossa pesquisa e a tarefa de Leitura e de Produção Escrita, em EAD, que lançamos aos estudantes de Tradução. Nesse ponto, do questionamento do mérito da tarefa que lhes seria apresentada, trouxemos-lhes também notícia de pesquisas em Linguística que tratam do tema dos processos envolvidos na compreensão de leitura e de simplificação de textos. Em meio a elas, temos reflexões sobre os temas da complexidade e da simplificação textual. Isso porque a simplificação de um texto pode servir de atalho para a construção de um conhecimento ad hoc, uma porta de acesso para algo que seja demasiado complexo em determinado momento da trajetória de aprendizagem de um indivíduo. Esse acesso facilitado inicial também poderia funcionar como um ponto motivador para o cidadão querer buscar mais letramento.

Letramento científico e simplificação textual

\subsection{Simplificação como "tradução"}

Conforme tentamos refletir com esses alunos de Letras, desde a época de Lutero, o embate entre ser fiel a um conhecimento e torná-lo acessível ao "vulgo" já ocorria. Ao propor que o texto da Bíblia deveria estar, não mais em latim, mas, sim, disponível em um alemão escrito que fosse compreensível pelos seus contemporâneos, Lutero pode ser considerado um precursor dessas reflexões (cf. HEIDERMANN, 2001). Por se tratar de um texto religioso e sagrado, chegava-se a indagar se aquela Bíblia de Lutero, escrita de acordo com o dialeto baixo alemão do povo germânico dos anos 1600, ainda seria uma fonte "verdadeira". Nesse embate, temos, de um lado, o povo inculto e, de outro, a Bíblia original, em latim, com os eruditos e letrados daquela época.

No nosso experimento, a tarefa de leitura e de reescrita foi apresentada aos estudantes de Letras/Tradução como uma oportunidade de mediarmos o diálogo entre essas partes em uma mesma língua a partir de um texto científico sobre doença de Parkinson (DP). Essa simplificação poderia ser entendida como uma "tradução", conforme considerações de diferentes teóricos dos Estudos da Tradução. Assim, a "lógica" da simplificação textual que efetuariam seria similar à de uma "tradução intralinguística", nos moldes do que refere, por exemplo, Umberto Eco (2007).

Ainda tratando da simplificação como uma tradução dentro da própria língua, a escola funcionalista [REISS; VERMEER, 1984] salienta a relevância da comunidade de destino dos textos traduzidos na tarefa de tradução. Conforme salientam Pasqualini et al. (2011, p. 31, “preponde- 
Maria José

Bocorny

Finatto

Aline Evers

Monica

Stefani

140

rantes são as regras e necessidades da comunidade leitora, e não as da língua de partida". Dessa forma, conhecer o perfil linguístico e cultural da comunidade que lerá o texto simplificado é fundamental para o sucesso das simplificações, porém, ainda são escassos os recursos disponíveis para delinear esses perfis. Os estudantes da disciplina, antes de realizarem o exercício, não somente tiveram contato prévio com textos sobre a DP, textos científicos e de divulgação para leigos, em suas diferentes línguas de estudo/formação (inglês, japonês, alemão, francês e espanhol) com especial destaque para o papel das terminologias empregadas, como também tiveram espaço para refletir sobre as necessidades linguísticas da comunidade alvo da simplificação.

\subsection{Desenho do exercício de simplificação}

Com suas simplificações de um português erudito para um português popular escrito, conforme determinamos, os estudantes deveriam atender a um público leitor com baixa escolaridade e poucas experiências de leitura que procurasse informações sobre um dado tema em sites da internet a partir de um buscador como o Google. $\mathrm{O}$ texto-fonte correspondeu a um texto disponível em um site da internet produzido por uma Associação de Pacientes, uma Associação Não-Governamental, sem fins lucrativos (uma ONG), de portadores da DP, a qual reúne e compartilha informações de médicos e de fontes científicas para leigos. Um exemplo de ONG seria a APARS - Associação dos Pacientes de Parkinson do Rio Grande do Sul (http://blogdaapars.blogspot.com.br).

Essa ONG, no nosso exercício com os estudantes de Letras/Tradução, fez o papel do cliente contratante do trabalho dessa "tradução". Seu associado seria o leitor-beneficiário do fictício trabalho. Na descrição da realização da tarefa e de seus desejados resultados para os estudantes, procuramos fornecer alguns subsídios para processos de simplificação textual. Retomamos os tópicos de aula sobre o papel das terminologias da área de Saúde e de Medicina envolvidas, mas também frisamos que apenas trocar termos técnicos por termos simples poderia ser insuficiente.

O experimento foi conduzido em três momentos consecutivos buscando aferir como se daria o desempenho da tarefa de leitura e de produção escrita dos futuros tradutores. Houve um momento inicial, o "ambiente off-line", no qual contariam apenas com folhas de papel e canetas para escrever. $O$ segundo momento aconteceu em um ambiente 
digital, bastante conhecido dos alunos, no cenário do nosso laboratório de Informática, com computadores conectados à internet e com o texto da tarefa e instruções disponíveis na plataforma Moodle UFRGS. O terceiro momento correspondeu à realização de um questionário introspectivo, no qual buscamos que os estudantes relatassem como realizaram a tarefa nas duas modalidades e que apreciassem a qualidade dos insumos para a sua tarefa de escrita. Todos os alunos envolvidos na tarefa já tinham tido contato com diferentes suportes de informação sobre o tema da DP e estavam envolvidos com a proposta de um pequeno glossário experimental multilíngue e colaborativo sobre esse tema, o qual pode ser acessado no site "Terminologias da Doença de Parkinson para

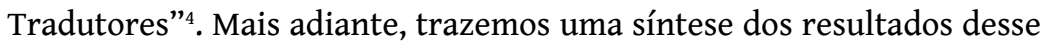
exercício. Passamos agora a comentar, ainda, sobre alguns pontos teó-

Letramento científico e simplificação textual ricos nele envolvidos a partir da revisão de alguns trabalhos do âmbito dos Estudos da Linguagem, em Linguística Aplicada.

\section{Letramento científico e a simplificação textual}

Como bem salienta Motta-Roth (2011), o acesso ao repertório de conhecimentos gerados pela ciência é um dos principais meios de qualificação das condições de vida em sociedade na contemporaneidade. Esse repertório fica registrado através da escrita, o que tornaria a produção de conhecimento e a competência linguística, interdependentes, de modo que não se poderia pensar em uma educação científica que não ocorresse concomitantemente a uma educação linguística. É nesse contexto que a autora trata do conceito de letramento científico. De acordo com o Instituto Nacional de Estudos e Pesquisas em Educação (INEP), letramento científico significa ter a "capacidade de empregar o conhecimento científico para identificar questões, adquirir novos conhecimentos, explicar fenômenos científicos e tirar conclusões baseadas em evidências sobre questões científicas" (INEP, 2016).

A partir dessas referências, uma simplificação textual visaria a auxiliar o processo de letramento científico, permitindo que todas as pessoas (sejam leigas ou não, com ou sem necessidades especiais) tivessem acesso ao um texto científico e conseguissem realizar todas as atividades incluídas nessa definição de letramento. Ainda assim, Motta-Roth (2009) retoma e situa a histórica polêmica antes citada entre vulgarizar e divulgar:

4 Disponível em http://www.ufrgs.br/textecc/traducao/terminologias 
Popularização, antes de ser uma vulgarização do conhecimento, é uma questão de grau de precisão ou tecnicalidade, e grau de recontextualização e de certificação da informação científica, em termos

Maria José

Bocorny

Finatto

Aline Evers

Monica

Stefani

142 da circulação que um fato científico sofre entre a sua criação e sua aceitação (HILGARTNER, 1990, p. 525-528). Em que ponto da cadeia de recontextualização as representações de conhecimento (como artigo, tabelas, citações, etc.) cessam de ser científicas e passam a ser popularização? (MOTTA-ROTH, 2009, p. 139).

Valendo o que aponta a autora, a simplificação poderia ser encaixada na ideia de uma recontextualização. Ainda assim, permaneceria a dificuldade de se determinar até que ponto as formas de reapresentação das informações textuais seriam uma "deturpação" do que foi dito pelo autor do texto original científico e em que ponto teríamos uma nova e original forma de dizer "a mesma coisa". Assim, este exercício pontual de pesquisa envolve uma miríade de reflexões filosóficas, epistemológicas e linguísticas.

Para Motta-Roth (2011), "a popularização de informações científicas em nosso país e o estudo do discurso nesse campo pode influenciar sobremaneira os modos de atuação política de profissionais das áreas humanas e sociais na sociedade" (MOTTA-ROTH, 2011, p. 22). Logo, ao refletirmos, com um simples exercício, com esses alunos, estávamos lidando com a complexa questão do letramento científico em duas vias: a via do letramento científico dos próprios tradutores em formação e a via do letramento científico do público-alvo de suas simplificações. Antes da produção e da edição dos seus textos, esses aprendizes de tradução, ao longo de quatro meses, foram apresentados ao tema da DP, buscando-se compreender os processos envolvidos no desenvolvimento da doença, assim como foram apresentados à bibliografia nacional e estrangeira sobre simplificação de vocabulário e de estruturas gramaticais. A seguir trazemos algumas referências por eles estudadas.

\subsection{Estudos sobre simplificação e tradução intralingual}

$\mathrm{Na}$ bibliografia estrangeira, há registros de pesquisas sobre readability ou legibilidade ou complexidade linguística pelo menos desde os anos 1920, conforme assinalam Davison e Green (1988, p. 1-4). Esses termos, vale frisar, já correspondiam a concepções distintas. Desde os anos 20, buscaram-se fórmulas ou modelos capazes de prever quais elementos 
textuais estariam mais associados à dificuldade de compreensão de determinados leitores, de modo que pudessem ser gerados textos de acesso mais facilitado para uma grande fatia de populações alfabetizadas, as quais, na época, tendiam a aumentar. Naturalmente, repercutiam também, no cenário dessas ideias de "facilitação", estreitas e intensas implicações históricas, interesses políticos, ideológicos e econômicos associados ao acesso à escolarização, à cultura letrada, ao incremento da produção em escala industrial e ao incentivo ao consumo para faixas maiores de população.

No Brasil, um dos primeiros linguistas a se debruçar sobre o tema da leitura funcional e da maior ou menor habilidade de leitura foi Mário Perini (PERINI, 1988), com o trabalho Tópicos discursivos e legibilidade (apud FULGÊNCIO, LIBERATO, 1992, p. 9). Perini propunha, então, que os

Letramento científico e simplificação textual estudantes de escolas brasileiras tivessem acesso a materiais de leitura graduados de acordo com o seu nível de escolaridade e com seus diferentes níveis de dificuldade de compreensão. Conectados a esse trabalho, vemos, por exemplo, os trabalhos de Kato (1982) e Kleiman (1995), produzidos especialmente ao longo dos anos 1980 e 1990. Ao mesmo tempo e a partir deles, vemos hoje um vasto e multifacetado alicerce de estudos sobre o tema da Leitura, especialmente no âmbito do Ensino. Esse corpo de conhecimento permite distinguir especificidades das noções de leitura, alfabetização, letramento, competência textual e competência leitora. Isso sem mencionarmos os inúmeros trabalhos sobre o tema da Leitura na área da Educação, Ensino de Língua Portuguesa e de Línguas Estrangeiras ou de Psicolinguística. Como já assinalava Perini (1988, p. 82), a dificuldade de um texto não é óbvia. Essa dificuldade não é algo apenas do texto, mas, sim, e, sobretudo, também do leitor e das condições que ele tem.

Levando em consideração esse quadro de conhecimentos, bastante conectado ao ensino de Leitura em língua materna, tentamos também tratar do tema da Leitura Tradutória com nossos estudantes e conectá-lo ao quadro dessas reflexões. Assim, trouxemos-lhes o tema conforme o tratamos em nosso trabalho recente (FINATTO et al., 2015). Muito mais do que simplesmente decodificar e recodificar, o tradutor está lidando com comunidades discursivas diferentes e com públicos de leitores que são também diferenciados. O tradutor, então, ao lidar com textos de temática científica, assume um papel intermediário, em que atua como um não especialista que interage, como leitor, com um 
Maria José

Bocorny

Finatto

Aline Evers

Monica

Stefani

144

conhecimento especializado. Por ocupar essa posição intermediária, aproximando-se do autor especialista e sendo, ele mesmo, um leigo, é o sujeito talvez mais capaz de compreender as dificuldades de se entregar um dado conhecimento, sem um devido letramento científico.

Além desse enfoque teórico, um tópico prático importante tratado com nossos alunos, já em meio aos estudos estrangeiros mais antigos sobre legibilidade e inteligibilidade, foi o Índice Flesch. Essa é uma medida, de base estatística, proposta na década de 1940 pelo austríaco Rudolph Flesch, que havia fugido da Europa nazista durante a guerra e se repatriado nos Estados Unidos. Sendo estrangeiro, acreditava que o plain English, ou seja, um inglês claro, objetivo, simples e sem ambiguidades, deveria ser o inglês usado em documentos oficiais para fácil compreensão de todos os cidadãos - principalmente por parte dos trabalhadores estrangeiros que acorriam em massa ao país. Esses alunos foram apresentados à concepção matemática dessa medida, que, grosso modo, correlaciona número de palavras, número de palavras diferentes e tamanhos de palavras de um dado texto. Sua escala vai de 10, muito difícil, a 100, muito fácil. Os estudantes também experimentaram ferramentas que medem o Índice Flesch de um texto e que funcionam on-line, além de ferramentas embutidas em editores de texto como o Word, da Microsoft, que são capazes de mostrar esse índice de modo automático (para mais detalhes, ver FINATTO et al., 2015).

\section{Relato do experimento}

\subsection{Cenário de pesquisa}

O experimento que realizamos partiu do pressuposto de que haveria, por diferentes motivos, um pouco ou menor engajamento desses estudantes de Letras/Tradução em tarefas de atividades de ensino em cenários de EAD em relação ao que já tínhamos verificado, em outras oportunidades, em tarefas presenciais sem quaisquer recursos digitais. A nossa hipótese era que haveria um certo descontentamento, desmotivação ou dificuldade desses alunos, especialmente com tarefas que envolvessem leitura de textos oferecidos na plataforma Moodle, mesmo em atividades de leitura dirigida. Assim, quisemos testar dois desenhos de tarefa de leitura e escrita que, em tese, teriam tudo para ser bem sucedidos, visto todo o preparo prévio e o conhecimento dos alunos sobre os temas envolvidos. 
A disciplina Terminologia Aplicada, com cujos alunos trabalhamos, no segundo semestre de 2015, teve como tema gerador a DP em Neurologia/Medicina. Essa disciplina é ofertada no quarto semestre do curso, o qual dura 8 semestres e meio. Trata-se de uma disciplina obrigatória, relacionada ao que chamamos, popularmente, de formação profissional para a "tradução técnica". Esses futuros profissionais precisam aprender a se apropriar, de forma rápida e eficiente, de terminologias, jargões e modos de dizer das mais diversas áreas, ao longo de suas carreiras, a fim de produzirem traduções e textos adequados às diferentes necessidades de comunicação de seus clientes.

A natureza do experimento foi qualitativa, para avaliar a qualidade do desempenho dos alunos na atividade de simplificação textual, e quantitativa, para observar os diferentes graus de desempenho. O questionário

Letramento científico e simplificação textual introspectivo foi elaborado para aferir, além de aspectos do produto final - os textos simplificados num formato off-line e noutro on-line -, alguns poucos dados socioeconômicos do grupo de estudantes e de suas preferências relacionadas ao hábito de leitura. Essa atividade de leitura e de escrita "tradutória" culminaria, ao final dos trabalhos da disciplina, em um mês, com a publicação on-line de um protótipo de glossário com termos da área ${ }^{5}$.

\subsection{Passos do experimento}

Além de textos escritos usuais, esses alunos foram expostos, em meses antes da realização da tarefa pontual, também ao texto original e traduções, para o português e para outras línguas, das legendas do filme norte-americano "O Amor e Outras Drogas", cuja personagem principal tem a DP. O texto científico médico, como artigos de revistas médicas, em um primeiro momento, foi apenas um coadjuvante na disciplina, mas esteve também presente como uma medida de referência para um texto complexo. Em seguida, foram lidas e "estudadas" bulas de vários medicamentos para tratamento da DP, trazidas pelos estudantes em suas respectivas línguas de trabalho e também em português, com especial atenção de todos para a parte das informações especialmente dirigidas aos pacientes, para eventuais pontos de maior dificuldade para leigos e para estratégias de facilitação do texto eventualmente adotadas pelos redatores em diferentes contextos culturais e legislativos.

5 Em construção, disponível na página Terminologias da Doença de Parkinson para Tradutores em http://www.ufrgs.br/textecc/traducao/terminologias/. 
Dessa forma, os alunos entraram em contato com diversos gêneros textuais que tratam da DP, de modo a compreender os contextos históricos e sociais nos quais a comunicação sobre a doença se dá. A finalidade

Maria José

Bocorny

Finatto

Aline Evers

Monica

Stefani

146 ao colocarmos os alunos em contato com esses gêneros foi a de fornecer uma variada gama de estilos e composições a serem observados e que seriam mobilizados e utilizados no decorrer da tarefa de adaptação, uma vez que os interlocutores dos textos fonte e original seriam diferentes.

Considerando a familiaridade dos alunos da disciplina com o tema da simplificação e da vulgarização de textos científicos e também com medidas estatísticas de complexidade textual, apresentamos-lhes, como texto-fonte, um texto por nós adaptado, do site da Academia Brasileira de Neurologia (da Sociedade Brasileira de Neurologia), sobre a DP. $O$ texto apresentado corresponde a uma síntese com 346 palavras e que, apesar de resumido, preservou o seu Índice Flesch de 16, considerado um texto muito difícil para compreensão de leitura:

A Doença de Parkinson é uma doença degenerativa do sistema nervoso central, crônica e progressiva. É causada por uma diminuição intensa da produção de dopamina, que é um neurotransmissor (substância química que ajuda na transmissão de mensagens entre as células nervosas). A dopamina ajuda na realização dos movimentos voluntários do corpo de forma automática, ou seja, não precisamos pensar em cada movimento que nossos músculos realizam, graças à presença dessa substância em nossos cérebros. Na falta dela, particularmente numa pequena região encefálica chamada substância negra, o controle motor do indivíduo é perdido, ocasionando sinais e sintomas característicos. O quadro clínico é composto basicamente de quatro sinais principais: tremores; acinesia ou bradicinesia (lentidão e diminuição dos movimentos voluntários); rigidez (enrijecimento dos músculos, principalmente no nível das articulações); instabilidade postural (dificuldades relacionadas ao equilíbrio, com quedas frequentes). Para o diagnóstico não é necessário, entretanto, que todos os elementos estejam presentes, bastando dois dos três primeiros itens citados. A Doença de Parkinson é tratável e geralmente seus sinais e sintomas respondem de forma satisfatória às medicações existentes. Esses medicamentos, entretanto, são sintomáticos, ou seja, eles repõem parcialmente a dopamina que 
está faltando e, desse modo, melhoram os sintomas da doença. Devem, portanto, ser usados por toda a vida da pessoa que apresenta tal enfermidade, ou até que surjam tratamentos mais eficazes. Ainda não existem drogas disponíveis comercialmente que possam curar ou evitar de forma efetiva a progressão da degeneração de células nervosas que causam a doença. Há diversos tipos de medicamentos antiparkinsonianos disponíveis, que devem ser usados em combinações adequadas para cada paciente e fase de evolução da doença, garantindo, assim, melhor qualidade de vida e independência ao enfermo. Também existem técnicas cirúrgicas para atenuar alguns dos sintomas da Doença de Parkinson, que devem ser indicadas caso a caso, quando os medicamentos falharem em controlar tais sintomas. Tratamento adjuvante com

Letramento científico e simplificação textual fisioterapia e fonoaudiologia é muito recomendado. 0 objetivo do tratamento, incluindo medicamentos, fisioterapia, fonoaudiologia, suporte psicológico e nutricional, é reduzir o prejuízo funcional decorrente da doença, permitindo que o paciente tenha uma vida independente, com qualidade, por muitos anos ${ }^{6}$.

O objetivo da tarefa proposta era de que os alunos simplificassem esse texto primeiro a mão (na versão off-line da tarefa) e, depois, com o uso de computador (na versão on-line). O seguinte perfil de leitor lhes foi apresentado no momento da tarefa, e deveria ser levado em conta:

- Faixa etária: adulto (mais de 25 anos);

- Sexo: feminino;

- Escolaridade: 8 anos de escola - ensino fundamental completo, ensino médio em curso - intermitente (inicia, mas interrompe por algum motivo a sua trajetória escolar, embora não tenha desistido de continuar), realizada apenas em escolas públicas;

- Ocupação: empregada doméstica, operária, comerciária;

- Hábitos de leitura: tem acesso ao jornal Diário Gaúcho (um jornal popular da cidade de Porto Alegre-RS) 3 vezes por semana; tem acesso à TV aberta, seu meio de informação é o Jornal Nacional, da Rede Globo, assiste a todas as novelas dessa emissora; tem acesso à internet pelo celular e tem perfil ativo na rede social Facebook.

6Adaptado do site da Academia Brasileira de Neurologia (Sociedade Brasileira de Neurologia): http:// www.cadastro.abneuro.org/site/conteudo.asp?id_secao=31\&id_conteudo=34\&ds_secao=Perguntas\%20e\%20Respostas 
Maria José

Bocorny

Finatto

Aline Evers

Monica

Stefani

148

O meio de divulgação do texto simplificado, para essa leitora fictícia, conforme explicado aos estudantes de Letras, seria o site da Associação Brasil Parkinson (http://www.parkinson.org.br), uma ONG de abrangência nacional que oferece informações para a população em geral sobre a doença. Os textos desse site, como de outras ONGs, já haviam sido lidos e estudados pelos estudantes.

\subsection{A tarefa no modo off-line}

A tarefa foi realizada em uma sala de aula convencional do Instituto de Letras, sem qualquer equipamento eletrônico ligado. Participaram dela 14 alunos que foram previamente informados que a sua realização integrava as atividades de avaliação normais da disciplina. Logo, seria um exercício "valendo nota". Aos alunos, entregamos cinco folhas, tamanho A4, contendo impressas as instruções para a tarefa, o texto original a ser simplificado, impresso em fonte grande, tamanho 14, e várias folhas pautadas para a transcrição do texto simplificado. Os alunos tiveram 40 minutos para escrever. Ao término da tarefa, os manuscritos foram recolhidos e os alunos dirigiram-se ao laboratório de informática, espaço previamente conhecido por todos. Ali, ao chegarem, repetiriam a mesma tarefa-fim, com o mesmo texto original, mas naquele momento, de um modo totalmente on-line. Os alunos só souberam dessa repetição no momento em que se instalaram frente a seus computadores e também foram informados de que o exercício, como o anterior, "também valia nota".

\subsection{A tarefa no modo on-line}

No laboratório, os alunos tinham computadores e internet à sua disposição. As instruções estavam no site da disciplina na plataforma Moodle. Depois de fazerem seu login, os alunos, além do comando da tarefa, tinham acesso a um arquivo do texto a ser simplificado em formato TXT. Esse formato foi escolhido para que, caso quisessem, pudessem submeter o texto original a uma ferramenta que aponta, automaticamente, os candidatos a termo de um texto, o software TermoStat Web 3.0. Essa ferramenta (http://termostat.ling.umontreal.ca) já havia sido experimentada em diferentes etapas da disciplina. Os textos simplificados, reescritos naquele momento, em um editor de texto Word, deveriam ser enviados via link de tarefa no Moodle, para posterior avaliação da professora. O tempo disponível para a tarefa foi também de 40 minutos. Ao final desse tempo, encerrava-se a aula daquele dia, ocorrendo o intervalo para almoço da UFRGS. 


\subsection{Questionários pós-tarefa}

Após a realização da tarefa, nas duas modalidades, os alunos receberam um questionário de prospecção impresso com 20 questões. Esse questionário seria respondido em casa e a atividade, como as outras, também "valia nota". Com as perguntas, objetivas, procuramos aferir a impressão dos alunos em relação à tarefa feita nos dois ambientes, off-line e on-line.

As perguntas iniciais (de 1 a 5) referiram-se a: faixa etária, sexo, hábito de leitura, quantos livros lê por ano e o que mais lê. Depois, havia a seção sobre leitura (perguntas 6 até 12), avaliando a percepção dos alunos em relação à leitura: se preferiam - ou achavam mais fácil - a leitura em tela ou em papel (pergunta 6), a contribuição do conhecimento prévio para a compreensão do texto lido nos modos off-line (pergunta 7) e on-line (pergunta 8), a facilidade de leitura dos enunciados das tarefas nos dois modos (perguntas 9 e 10) e a facilidade

Letramento científico e simplificação textual de leitura do texto para simplificação lido em papel (pergunta 11) e em tela (pergunta 12). A seção sobre escrita (perguntas 13 até 20) pedia que avaliassem seu próprio desempenho na tarefa manuscrita (pergunta 13) e ao computador com conexão à internet (pergunta 14), a contribuição do conhecimento prévio sobre o assunto para a qualidade da reescrita no modo off-line (15), o grau de importância 1) do conhecimento prévio, 2) da realização da tarefa em modo off-line antes de repeti-la no modo on-line e 3) da lista de termos no TermoStat (pergunta 16), a preferência por algum dos modos na realização da tarefa (pergunta 17), a importância da lista de termos para simplificar o texto no modo on-line (18), a importância do acesso a recursos da internet e do ambiente on-line nas decisões de simplificação (19) e as ferramentas e/ou passos/recursos de apoio cumpridos pelo aluno para simplificar o texto no modo on-line (20).

Os resultados desse questionário, respondido por 14 alunos, são resumidos nas Tabelas 1, 2 e 3, a seguir:

\begin{tabular}{|lc|lc|}
\hline \multicolumn{4}{|c|}{ Preferência na realização da tarefa } \\
\hline Apenas on-line & $28,5 \%$ & Apenas off-line & $21,4 \%$ \\
\hline Indiferente aos dois modos & $28,5 \%$ & Gostou de ter feito as duas & $21,4 \%$ \\
\hline
\end{tabular}

Tabela 1 - Preferência pelos modos on e off-line. Fonte: As autoras.

\begin{tabular}{|c|c|c|c|}
\hline \multicolumn{4}{|c|}{$\begin{array}{c}\text { Acesso a recursos da Internet + ambiente on-line: } \\
\text { influência nas decisões de simplificação }\end{array}$} \\
\hline Muito & $15,3 \%$ & Nem muito nem pouco & $23 \%$ \\
\hline Um pouco & $53,8 \%$ & Nem um pouco & $7,6 \%$ \\
\hline
\end{tabular}

Tabela 2 - Influência de recurso na tarefa de simplificação. Fonte: As autoras. 
Maria José

Bocorny

Finatto

Aline Evers

Monica

Stefani

150

\begin{tabular}{|c|}
\hline Estratégias e passos na simplificação - on-line \\
\hline Usei sinônimos simples para os termos e palavras partindo da minha intuição ........92,8\% \\
\hline Diminuí o tamanho do texto \\
\hline Li o texto rapidamente \\
\hline Comparei o texto original e o meu texto simplificado antes de finalizar a tarefa ......85,7\% \\
\hline 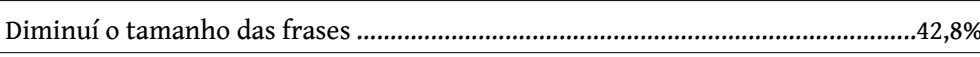 \\
\hline 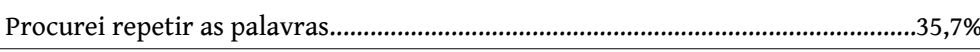 \\
\hline Consultei o Google para saber/entender alguma palavra desconhecida...............35,7\% \\
\hline Fiz um copia-e-cola do texto em .txt para o Word e já apaguei o que deveria sair ....35,7\% \\
\hline Fiz a simplificação sem grandes reflexões ou buscas, apenas improvisei ..............35,7\% \\
\hline Evitei pronomes \\
\hline Usei a Internet para achar e decidir sobre quais sinônimos simples usar.............21,4\% \\
\hline Inseri/apaguei elementos após verificar a lista do TermoStat ..............................14,2\% \\
\hline Não li o texto de novo, pois lembrava de tudo.......................................................14,2\% \\
\hline Tentei fazer tudo o mais rápido possível, para poder sair logo .............................7,1\% \\
\hline
\end{tabular}

Tabela 3 - Resultados do questionário pós-tarefa. Fonte: As autoras.

Essas respostas foram contrastadas com os textos produzidos na simplificação propriamente dita.

\subsection{Resultados do experimento}

Para a análise dos textos simplificados, numeramos cada texto (1 a 14), desidentificamos a autoria dos mesmos e fizemos a sua separação pela denominação "off-line" e "on-line". Essa análise foi independente da avaliação do exercício por parte da professora da disciplina. Para os do modo off-line, procedemos à digitação dos textos no Microsoft Word, preservando seu conteúdo. Os textos feitos no modo on-line também não foram corrigidos.

\subsubsection{Diferenças entre os dois modos}

Cruzando o texto original, complexo, os textos produzidos, simplificados, e a Tabela 1, verificamos alguns dados esperados. Um dos resultados, por exemplo, foi que a maioria dos textos produzidos com recursos on-line são mais longos, com um maior número de palavras do que os produzidos off-line. A partir desse dado, podemos inferir que escrever manualmente, tendo-se lido pela primeira vez um texto, fez com que os estudantes fossem mais sintéticos, seja por cansaço da escrita manual ou mesmo pela impossibilidade de muitas reescritas, 
dada a pressão de tempo. Como bem sabemos, no meio on-line, é possível recortar, copiar, colar, arrastar, deletar e digitar novamente de forma ilimitada.

Outro dado interessante é que o número de palavras por frase na versão on-line diminuiu, ou seja, as frases ficaram mais curtas, enquanto os textos ficaram mais longos. Isso demonstra que os conteúdos foram segmentados de formas diferentes nas versões on-line e off-line. Enquanto os textos produzidos manualmente ficaram MENORES e com frases MAIORES, os textos produzidos com o auxílio de ferramentas ficaram MAIS LONGOS, mas com frases MENORES.

Os textos que apresentaram diferenças entre os modos off-line e on-line nas faixas de dificuldade do Índice Flesch foram os textos 7 e 8, com 137 e 209 palavras (Índice Flesch 23 - Muito Difícil - e 42 - Difícil,

Letramento científico e simplificação textual respectivamente) para 208 e 198 (Índice Flesch 32 - Difícil - e 52 - Fácil, respectivamente). A seguir, para apreciação, apresentamos um trecho do Texto 8, cuja versão simplificada no modo on-line foi considerada fácil:

\begin{tabular}{|l|l|}
\hline \multicolumn{1}{|c|}{ Texto 8 - Modo off-line } & \multicolumn{1}{c|}{ Texto 8 - Modo on-line } \\
\hline $\begin{array}{l}\text { Apesar de não ter cura, a Doença } \\
\text { de Parkinson tem tratamento, que }\end{array}$ & $\begin{array}{l}\text { Apesar de não ter cura, a doença } \\
\text { serve para melhorar os sintomas, } \\
\text { tem tratamentos que diminuem }\end{array}$ \\
eu seja, ele alivia os problemas que & os sintomas_e o as dificuldades \\
tomados por toda a vida do pacien- & geradas por eles. Existem remédios \\
te. Existem também cirurgias que & ram a condição geral do paciente, \\
são recomendadas em alguns casos, & e existem técnicas cirúrgicas que \\
normalmente quando os remédios & atenuam alguns dos sintomas nos \\
não fazem efeito, mas, assim como & casos em que os medicamentos não \\
eles, seu objetivo não é curar, ape- & fazem efeito. \\
nas melhorar a vida do paciente. & \\
\hline
\end{tabular}

Provavelmente, a possibilidade de editar com mais rapidez no computador teria gerado um segmento de texto com menos palavras, mantendo-se as informações julgadas relevantes. A estrutura de frase ficou mais clara na segunda versão, com a diminuição do uso do pronome relativo "que" ( $42,8 \%$ dos estudantes estavam trabalhando na tarefa de simplificação procurando diminuir o tamanho das frases). Vejamos um exemplo do Texto 9, considerado mais difícil pelo parâmetro do Índice Flesch: 
Maria José

Bocorny

Finatto

Aline Evers

Monica

Stefani

\begin{tabular}{|c|c|}
\hline odo off-line & Texto 9 - modo on-line \\
\hline $\begin{array}{l}\text { É possível tratar a doença } \\
\text { com medicações, que repõem } \\
\text { parte da dopamina que está } \\
\text { faltando no organismo, assim, } \\
\text { melhorando seus sintomas. } \\
\text { Fisioterapia e fonoaudiologia } \\
\text { também são recomendados no } \\
\text { tratamento. }\end{array}$ & $\begin{array}{l}\text { Tratamento com fisioterapia e fono- } \\
\text { audiologia é muito recomendado. } 0 \\
\text { objetivo do tratamento, incluindo medi- } \\
\text { camentos, fisioterapia, fonoaudiologia, } \\
\text { suporte psicológico e nutricional, é re- } \\
\text { duzir o prejuízo decorrente da doença, } \\
\text { permitindo que o paciente tenha uma } \\
\text { vida independente, com qualidade, por } \\
\text { muitos anos. }\end{array}$ \\
\hline
\end{tabular}

Nesses excertos, é possível ver o que mencionamos anteriormente: o modo on-line, aparentemente pela facilidade de digitação e de visualização de segmentos textuais, permite que o texto seja um pouco mais longo, com mais informações, mas nem por isso mais difícil. Pelo contrário, ele se mostra até mais fácil (por exemplo, as repetições de palavras, que são um recurso de simplificação importante - e que foram utilizadas por $35,7 \%$ dos alunos nesta tarefa, segundo os dados do questionário - aparecem em "fonoaudiologia" e "fisioterapia" na versão on-line).

Quanto a estratégias empregadas pelos estudantes, a maioria $(85,7 \%)$ estava trabalhando com a ideia de que um texto menor seria mais fácil, mas, pelo exemplo citado, vemos que isso não se concretizou na tarefa. A intuição linguística dos estudantes também merece destaque por ter sido, conforme relataram, o principal guia de suas escolhas $(92,8 \%)$, em contraposição aos $35,7 \%$ que consultaram o Google para entender alguma palavra desconhecida, aos $21,4 \%$ que usaram a internet para decidir sobre quais sinônimos simples usar, e aos 14,2\% que inseriram ou apagaram elementos após verificar a lista de prováveis terminologias gerada pela ferramenta TermoStat. Assim, concluímos que esses estudantes tenderiam a tomar como referência sua própria expertise linguística para o trabalho de simplificação. O recurso a ferramentas on-line seria-lhes apenas um auxílio ocasional, já que, para 53,8\% dos respondentes, a importância do acesso à ferramenta on-line TermoStat, bem como a outros recursos nesse ambiente, afetou apenas um pouco as decisões de simplificação. Especificamente quanto à ferramenta TermoStat, 21,4\% dos estudantes acharam-na totalmente dispensável para a tarefa, provavelmente por já conhecerem a terminologia da área. $\mathrm{Ne}$ - 
nhum aluno relatou ter recorrido aos resultados do Índice Flesch em qualquer etapa de realização da tarefa.

Ainda sobre os resultados do questionário, é interessante observar que os alunos, no geral, não sentiram diferença de realizar a tarefa entre os dois modos: $28,5 \%$ manifestaram-se indiferentes; $21,4 \%$ disseram ter gostado de fazer a tarefa nos dois modos; $28,5 \%$ preferiram apenas o modo on-line, e 21,4\%, apenas o modo off-line. Esses dados podem ser relacionados aos modos de leitura, cujas preferências relatadas foram: 7,1\% preferem ler apenas on-line, 28,5\%, apenas em papel, e, para Letramento a maioria $(64,2 \%)$, nenhuma das duas formas é melhor do que a outra. Essa amostragem sinaliza-nos que esses alunos de Letras/Tradução já possuem uma expertise digital, isto é, já demonstram uma familiaridade maior com a leitura e com a escrita feitas em computador e, assim, talcientífico e simplificação textual vez, também com a realização de tarefas de aula neste ambiente. Ademais, a maioria evidenciou o domínio dos recursos oferecidos e confiança na sua própria capacidade linguística para a tarefa de simplificação, apesar de toda a discussão realizada ao longo do semestre sobre as complexidades envolvidas nas escolhas de edição e retextualização.

\section{Considerações finais}

A partir desse experimento, dado o bom engajamento dos alunos e até o seu entusiasmo com a tarefa, as atividades de simplificação textual confirmam-se importantes, não somente como uma forma de desenvolver essa habilidade durante a formação profissional de futuros profissionais do texto, mas também como um veículo para a crucial popularização da ciência, considerando inclusive "a sobrevivência da própria ciência (digamos, 'erudita'), esta vista como um bem que deve ser produzido e cujo acesso deve ser democratizado em sociedade" (MOTTA-ROTH, 2009, p. 136). Diante dos resultados apresentados, vimos que os alunos envolvidos possuem expertise digital e letramento científico, apresentando familiarização com a temática da DP (50\% dos respondentes consideraram que o conhecimento prévio contribuiu grandemente para a qualidade dos textos simplificados nos dois ambientes) após alguns meses manipulando textos sobre o assunto. Assim, vemos que, para essa parcela de estudantes de Letras da UFRGS, a riqueza de recursos oferecida pelo ambiente on-line não foi responsável, por si só, pela qualidade da produção dos textos: a intuição linguística dos estudantes teve peso maior, com as ferramentas atuando como auxiliares na atividade de simplificação. 
Todavia, é inegável que trabalhar ao computador, durante esta tarefa, fez com que os textos fossem mais bem manejados e, consequentemente, resultassem em produções, de fato, mais simples, sendo o número de

Maria José

Bocorny

Finatto

Aline Evers

Monica

Stefani

154 palavras maior ou menor.

O experimento relatado neste artigo propõe a reflexão e a discussão do papel do tradutor como intermediário no processo de acesso à informação nos cursos de bacharelado e de formação de tradutores. É um nicho no mercado de trabalho ainda não detectado dentre as inúmeras opções editoriais que se colocam aos estudantes. Ainda sob o aspecto teórico, abarcar a simplificação textual como uma tradução intralingual, dentro da língua portuguesa, é de extrema relevância dentro dos currículos do bacharelado e também para fomentar as pesquisas linguísticas que tentam dar conta da simplificação. Para Jakobson (2007), a tradução intralingual é também uma reformulação. Essa reformulação, segundo o autor, pode extrapolar o meio escrito e se traduzir em transcriações expressas em outros suportes, como, por exemplo, a oralização de textos ou a aplicação de técnicas gráficas para transformar texto em imagem. Evidentemente, nos cursos de bacharelado e no caso da simplificação, ainda estamos no nível de reformular um texto por outro texto, levando em conta aspectos sintáticos e lexicais. Mas, futuramente, é desejável que a simplificação textual seja fortemente relacionada com a tradução intersemiótica, envolvendo outras disciplinas, como as áreas da educação e das artes plásticas, com a finalidade de melhor compreender como os que possuem ainda baixo letramento poderiam se beneficiar de suportes aos textos que envolvessem grafismos e som.

Dado os atuais números alarmantes relacionados ao alfabetismo funcional no Brasil, o experimento descrito neste artigo, que envolveu a simplificação de um texto em português sobre a DP para um determinado perfil de leitor, apesar de inicialmente ter contado com a participação de apenas 14 alunos, torna-se uma fonte de dados e de hipóteses para pesquisas futuras. Houve diferenças entre a leitura em papel e a leitura em tela? Embora a maioria dos alunos tenha se mostrado indiferente aos dois modos, percebemos, pelas simplificações textuais produzidas, que houve, sim, diferenças no modo como o texto foi tratado (lido e reescrito) para a simplificação. Em tela, houve maior facilidade de trabalho (escrita), permitindo recortes, mudanças de ordem de frases e parágrafos, confirmações de significados e de informações com os recursos on-line (leitura). 
No modo em papel, diante da ausência dos recursos de pesquisa e contando apenas com seu conhecimento prévio e expertise linguística, os alunos sentiram os limites, mas nem por isso deixaram de produzir uma simplificação adequada (visto que já estavam familiarizados com a temática do texto). Alterar a ordem de realização das tarefas, isto é, submeter os alunos à realização da tarefa primeiro no modo on-line e depois no modo off-line, geraria mudanças significativas na percepção dos alunos? É uma possibilidade a ser testada. Dividir a turma em dois grupos e deixá-los fazer a tarefa de simplificação somente em um dos modos (Grupo 1 no modo on-line e Grupo 2 no modo off-line) também poderia engendrar resultados e perspectivas diferentes? Essas são alternativas a serem testadas em momentos futuros, com alunos de outras disciplinas.

A partir dos diversos estudos citados sobre leitura (um tópico

Letramento científico e simplificação textual tão complexo por si só, devido às idiossincrasias do ato de leitura de cada pessoa e dos diversos propósitos dessa atividade - leitura para aprendizado, leitura para tradução, leitura para revisão, leitura para entretenimento, entre outras), relacionar este tema com a formação de profissionais que lidarão majoritariamente com textos de temática técnico-científica é imprescindível, se quisermos colocar em prática modos de mitigar as desigualdades ainda visíveis, permitindo um acesso efetivo ao conhecimento por parte da maioria da população brasileira. Esse acesso efetivo ao conhecimento, por sua vez, é uma tarefa que transcende a mera aquisição de computadores e dispositivos móveis com acesso à internet: é aí que a simplificação textual parece ser uma alternativa viável, que vem ao encontro da necessidade de dar atenção a perfis de leitores mais realistas (como o da leitora de escolaridade limitada que relatamos na nossa pesquisa, "cliente" da simplificação proposta). Abominando as ideias ainda recorrentes de que simplificar é "nivelar por baixo", procuramos demonstrar com nossa pesquisa a importância de trabalhar essa habilidade nos cursos de Letras (tanto na formação de tradutores como na de educadores). De fato, a simplificação textual e a ideia de uma acessibilidade textual e terminológica são caminhos para implantar ações que democratizem o acesso ao conhecimento, dinamizando e transpondo os resultados das pesquisas produzidas no âmbito da academia para a realidade da população brasileira em geral, ajudando-a no seu processo de amadurecimento linguístico. Afinal, simplificar um texto pode, sim, ser uma atitude impulsionadora para que, a partir de um ponto inicial, o 
indivíduo busque - e consiga - aumentar seus níveis de letramento. Nesse contexto, tarefas como essa podem contribuir para promover o letramento científico do futuro tradutor, salientando-se que esse é um

Maria José

Bocorny

Finatto

Aline Evers

Monica

Stefani

156 percurso de desenho não trivial.

\section{Agradecimentos}

As autoras agradecem à Secretaria de Educação a Distância da UFRGS (SEAD-UFRGS) pela bolsa de pesquisa concedidada, ao CNPq, à CAPES - Programa STIC-AMSud, Projeto RITA (047/2014), à FAPERGS e ao PPG-Letras-UFRGS.

\section{REFERÊNCIAS}

ACADEMIA Brasileira de Neurologia - Sociedade Brasileira de Neurologia. Disponível em:<http://www.cadastro.abneuro.org>.

APARS - Associação dos Pacientes de Parkinson do Rio Grande do Sul. Disponível em: <http://blogdaapars.blogspot.com.br>.

BRASIL. Instituto Nacional de Estudos e Pesquisas em Educação INEP. Definição de letramento científico. Disponível em: <http:// download.inep.gov.br/download/internacional/pisa/2010/letramento_cientifico.pdf> Acesso em 11 fev. 2016.

DAVISON, A., \& GREEN, G. Linguistic complexity and text comprehension - readability issues reconsired. New Jersey: Lawrenc e Erlbaum Associates, 1988.

DE REZENDE VERGARA, Moema. Contexto e Conceitos: História da ciência e "vulgarização científica" no Brasil do século XIX. INCI, Caracas, v. 33, n. 5, p. 324-330, mayo 2008. Disponível em: <http:// www.scielo.org.ve/scielo.php?script=sci_arttext\&pid=S0378$-18442008000500004 \& \operatorname{lng}=$ es\&nrm=iso>. Acesso em 24 abr. 2016.

ECO, U. Quase a mesma coisa: experiências de tradução. Rio de Janeiro: Record, 2007 
FINATTO, M.J.B, STEFANI, M., PASQUALINI, B., CIULLA, A., EVERS, A., SORTICA, M. Leitura: um guia sobre teoria(s) e prática(s). Porto Alegre: UFRGS, 2015.

FULGÊNCIO, Lúcia, LIBERATO, Yara. Como facilitar a leitura: como se processa a leitura; orientação para textos didáticos; aspectos discursivos. São Paulo: Contexto, 1992.

Letramento

HEIDERMANN, W. (Org.): Clássicos da Teoria da Tradução. Vol. I científico e Alemão-Português. UFSC, Núcleo de Tradução, 2001.

simplificação textual

JAKOBSON, Roman. Linguística e Comunicação. 24. ed. São Paulo: Cultrix, 2007.

KATO, Mary. Reconhecimento instantâneo e processamento em leitura. Uberaba, MG (Série Estudos, 8), 1982.

KLEIMAN, Angela B. Modelos de letramento e as práticas de alfabetização na escola. In: KLEIMAN, Angela B. (Org.). Os significados do letramento. Campinas, S.P.: Mercado de Letras. 294 p. p. 15-61, 1995.

MOTTA-ROTH, Désirée. Letramento científico: sentidos e valores. In: Notas de Pesquisa, Santa Maria, RS, v. 1, n. 0, p. 12-25, 2011.

. Popularização da ciência como prática social e discursiva. In: MOTTA-ROTH, D.; GIERING, M. E. (Orgs.). Discursos de popularização da ciência. Santa Maria, RS: PPGL Editores, 2009. 343 p. (Coleção HiperS@beres, 1). ISSN 2177-6385.

PASQUALINI, Bianca F., SCARTON, Caroline E., FINATTO, Maria José B. Comparando Avaliações de Inteligibilidade Textual entre Originais e Traduções de Textos Literários. In: Proceedings of the 8th Brazilian Symposium in Information and Human Language Technology, p. 30-39, Cuiabá, MT, Brasil, Outubro 24-26, 2011. Sociedade Brasileira de Computação. Disponível em: http://www.aclweb.org/anthology/ W11-4504. Acesso em 29 abr. 2016 
PERCEPÇÃO PÚBLICA DA CIÊNCIA E TECNOLOGIA. Disponível em: http://www.mct.gov.br/upd_blob/0214/214770.pdf Acesso em 11 fev. 2016.

Maria José

Bocorny

PERINI, Mário A. A leitura funcional e a dupla função do texto

Finatto didático. In: ZILBERMAN, Regina; SILVA, Ezequiel T. (Org.). Leitura: Perspectivas interdisciplinares. São Paulo: Ática, 1988.

Aline Evers

PESQUISA CULTURA NO BRASIL. Fecomércio RJ. Disponível em: Monica <http://www.fecomercio-rj.org.br/publique/media/Pesquisa\%20 Stefani Cultura.pdf> Acesso em 11 fev. 2016.

158 REISS, Katharina, VERMEER, Hans. J. Grundleging einer allgemeinen Translationstheorie, Tübingen: Niemeyer of Difference, Londres \& Nova Iorque: Routledge, 1984.

TERMINOLOGIAS da Doença de Parkinson para Tradutores. Disponível em:< http://www.ufrgs.br/textecc/traducao/terminologias> 